This item was submitted to Loughborough's Research Repository by the author.

Items in Figshare are protected by copyright, with all rights reserved, unless otherwise indicated.

\title{
Characterisation of an antenna system implanted into a limb phantom for monitoring of bone fracture healing
}

\section{PLEASE CITE THE PUBLISHED VERSION}

http://dx.doi.org/10.1109/LAPC.2016.7807607

\section{PUBLISHER}

(C) IEEE

\section{VERSION}

AM (Accepted Manuscript)

\section{PUBLISHER STATEMENT}

This work is made available according to the conditions of the Creative Commons Attribution-NonCommercialNoDerivatives 4.0 International (CC BY-NC-ND 4.0) licence. Full details of this licence are available at: https://creativecommons.org/licenses/by-nc-nd/4.0/

\section{LICENCE}

CC BY-NC-ND 4.0

\section{REPOSITORY RECORD}

Panagamuwa, C.J., Symeon Symeonidis, and W.G. Whittow. 2019. "Characterisation of an Antenna System Implanted into a Limb Phantom for Monitoring of Bone Fracture Healing”. figshare. https://hdl.handle.net/2134/24624. 


\title{
Characterisation of an Antenna System Implanted into a Limb Phantom for Monitoring of Bone Fracture Healing
}

\author{
Symeon Symeonidis, William G. Whittow and Chinthana Panagamuwa \\ Wolfson School of Mechanical, Electrical and Manufacturing Engineering, Loughborough University, Loughborough, \\ Leicestershire, UK \\ S.Symeonidis@lboro.ac.uk,w.g.whittow@1boro.ac.uk,c.j.panagamuwa@lboro.ac.uk
}

\begin{abstract}
An antenna system consisting of two implanted monopoles has been investigated. The proposed structure has been simulated in a cylindrical three layer limb phantom and the $S_{11}$ and $S_{21}$ responses of the system have been evaluated for the 0.5 to $5 \mathrm{GHz}$ frequency range. This process occurred as the bone fracture that was introduced in the middle of the phantom gradually healed turning from blood to bone marrow and bone cortical in five discrete steps.
\end{abstract}

Keywords - implanted antennas, bone phantoms, fracture monitoring

\section{INTRODUCTION}

Implanted antennas is a research topic that has been gaining interest over the past decade. The most common frequency band used is the Medical Device Radiocommunications Service (MedRadio) operating at $401-406 \mathrm{MHz}$ [1]-[3] and the Industrial, Scientific and Medical (ISM) [4]-[6] operating at 2.44 to $2.46 \mathrm{GHz}$ frequency range. Most of the implants are often incorporated under the skin, fat and muscle tissues [7][13]. Other include implantation beneath the skull [14], intraocular implementation of antennas for retinal prosthesis [15], ingestible capsule antennas for the monitoring of human intestines [16], antennas operating in the GPS frequency range for the localization of people suffering from Alzheimer's disease [17] and antennas that are used for wireless powering sensors and implants inside the human body [18]. Proper design and manufacture can prove a challenging task for engineers but with multiple benefits in the field of medicine. Some of the most common impediments include the difficulty of transmitting information from inside of the body to external sources and vice versa, the limitations in terms of available space inside the body and the compulsory biocompatibility of the materials used for the creation of the implants. In most cases an approach among scientists from several fields including electromagnetics and biology is required in order for an implanted device to be designed and tested properly. Over the last two decades a variety of implanted antenna geometries have been proposed offering a good tradeoff between frequency of operation, antenna size and efficiency.
In this work, an implanted antenna system is proposed that monitors the healing of bone fractures. The biological process of fracture healing is a complicated process that if not monitored and evaluated continuously the first 4 weeks after the trauma, often leads to failure of bone restoration to its pre fractured state [19]. Healing depends, amongst others, on the number of discrete fractures, the type of bone and the patient's age and gender [20], [21]. The proposed antenna system could provide doctors with continuous information regarding the state of the fractured bone, reducing the required $\mathrm{x}$-rays and $\mathrm{CT}$ scanning. Additionally, the proposed structure can provide support to the damaged bone similar to the metal pins used by the doctors to heal fractured limbs.

\section{ANTENNA DESIGN WITHIN A THREE LAYER LIMB PHANTOM}

The proposed antenna system consists of two monopoles. The length of each monopole was $3 \mathrm{~cm}$ and they were attached to two $4 \times 3.4 \mathrm{~cm}$ groundplanes as shown in Figure 1. A gap of $2 \mathrm{~mm}$ to assure that there will be no contact between the groundplanes in future measurements was selected. The distance between the monopoles was $2 \mathrm{~cm}$ as it was found in previous research to be the optimal distance for proper communication within the fracture [21]. For the simulations a three layer coaxial limb phantom was used consisting of bone marrow, bone cortical and muscle tissues. The central frequency of simulation was set at $3 \mathrm{GHz}$, this is due to the diameter of the bone marrow and the penetration depth of the monopoles into the phantom. The dimensions of each layer in the coaxial phantom were given according to measurements taken on a lamb joint that will be used for analysis as a phantom in future work. Table 1 shows the dielectric properties that were selected for each layer of the phantom at $3 \mathrm{GHz}$. The permittivity and conductivity of the phantom layers were frequency depended, their values changed for each simulated frequency according to the measurement results found in [22] [23] for the range of 0.5 to $5 \mathrm{GHz}$. 


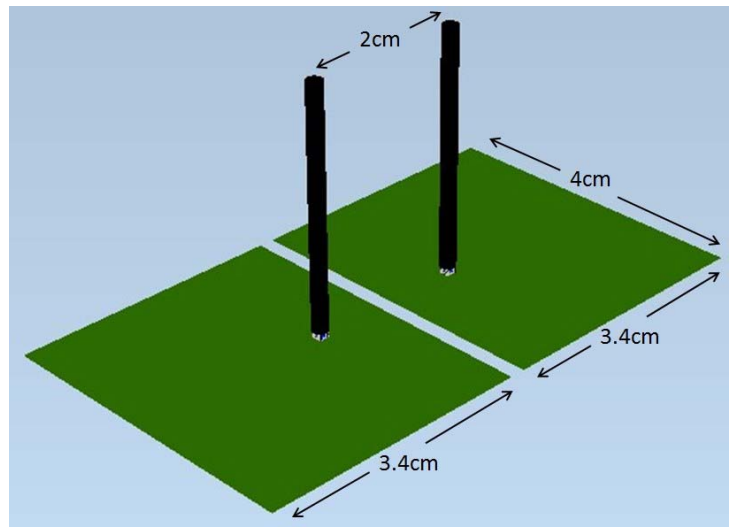

Figure 1: The proposed antenna system

Each of the cylinders had $15 \mathrm{~cm}$ length, the outer cylinder had $4 \mathrm{~cm}$ radius, the middle $3 \mathrm{~cm}$ and the inner $2 \mathrm{~cm}$. The fracture was introduced in the middle of the phantom in the bone cortical and bone marrow layers. The fractured area in the bone marrow layer was considered a cylinder and the top part of the bone cortical area was represented as a block of bone (see Figure 2). The block part will represent the drilling point on the surface of the bone where a blood simulating liquid will be injected into the bone marrow in future measurements.

Table 1: The dielectric properties used for the three layered bone phantom at $3 \mathrm{GHz}[22][23]$

\begin{tabular}{|c|c|c|}
\hline & $\begin{array}{c}\text { Relative } \\
\text { Permittivity } \\
\varepsilon_{r}\end{array}$ & $\begin{array}{c}\text { Conductivity } \\
\sigma,(\mathrm{S} / \mathrm{m})\end{array}$ \\
\hline Muscle & 52.05 & 3.04 \\
\hline Bone Marrow & 5.23 & 0.12 \\
\hline Bone Cortical & 11.06 & 0.50 \\
\hline Blood & 57.35 & 3.04 \\
\hline
\end{tabular}

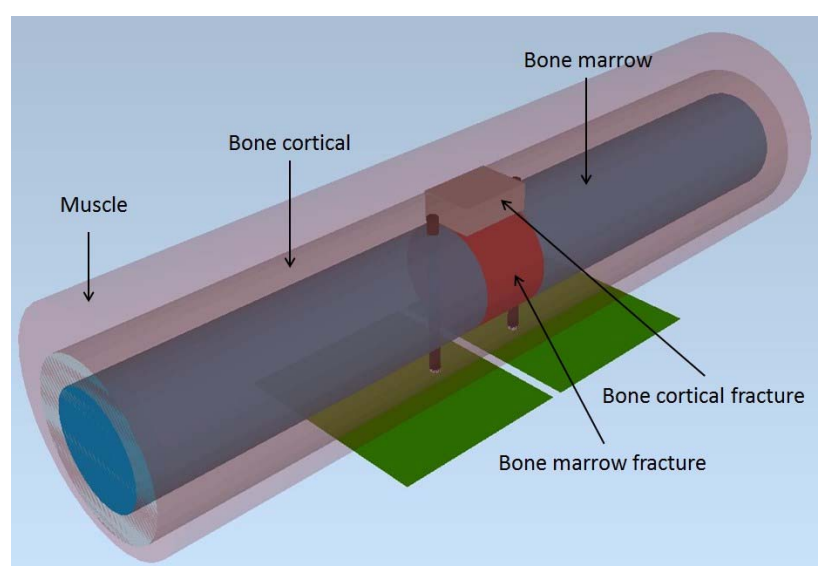

Figure 2: The limb phantom and the position of the fracture

Five different states were considered, emulating the condition of the fracture as it heals, turning from blood to bone. At the initial state, the dielectric properties of blood were given to the fracture, changing by a $25 \%$ step towards the properties of marrow and cortical until the bone reached a completely healed state. At the fifth step the bone is considered fully healed and the fracture no longer exists inside the phantom.

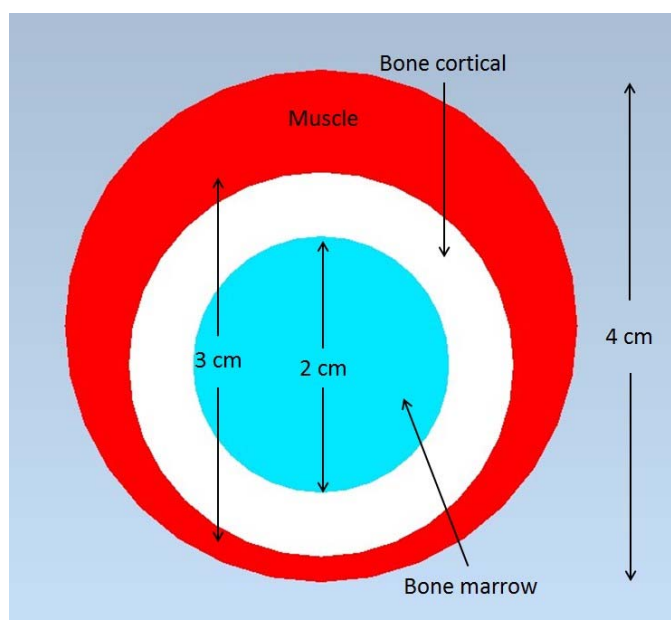

Figure 3: Limb phantom dimensions

Table 2: The dielectric properties of the fracture during the healing progress at $3 \mathrm{GHz}$

\begin{tabular}{|c|c|c|c|c|}
\hline & \multicolumn{2}{|c|}{ Bone marrow fracture } & \multicolumn{2}{c|}{ Bone cortical fracture } \\
\hline $\begin{array}{c}\text { Bone } \\
\text { Damage }\end{array}$ & $\begin{array}{c}\text { Relative } \\
\text { Permittivity } \\
\varepsilon_{r}\end{array}$ & $\begin{array}{c}\text { Cond. } \\
\sigma,(\mathrm{S} / \mathrm{m})\end{array}$ & $\begin{array}{c}\text { Relative } \\
\text { Permittivity } \\
\varepsilon_{r}\end{array}$ & $\begin{array}{c}\text { Cond. } \\
\sigma,(\mathrm{S} / \mathrm{m})\end{array}$ \\
\hline $100 \%$ & 57.35 & 3.04 & 57.35 & 3.04 \\
\hline $75 \%$ & 44.32 & 2.31 & 45.77 & 2.40 \\
\hline $50 \%$ & 31.29 & 1.58 & 34.20 & 1.77 \\
\hline $25 \%$ & 18.26 & 0.85 & 22.63 & 1.13 \\
\hline $0 \%$ & 5.23 & 0.12 & 11.06 & 0.50 \\
\hline
\end{tabular}

\section{SIMULATION RESULTS OF THE PROPOSED STRUCTURE}

For the simulation of the proposed structure, the EMPIRE XPU EM solver was used. The fracture occupied the $2 \mathrm{~cm}$ distance between the monopoles. The monopoles were connected to the groundplane on the outside of the muscle layer and were implanted $3 \mathrm{~cm}$ deep into the phantom, reaching the top edge of the bone marrow from bottom (see Fig. 2). Figure 4 shows the changes in the $S_{11}$ response of the antenna as the permittivity and the conductivity of the fracture changes from blood to bone cortical and bone marrow in five steps. 


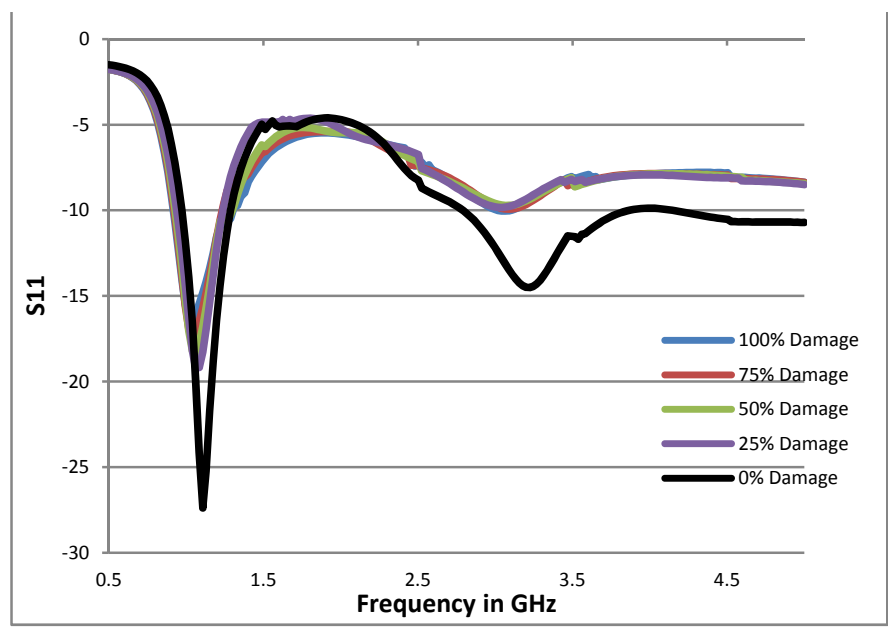

Figure 4: The $S_{11}$ response of the antenna system for the five steps of the bone fracture condition

The results of the simulation show that the $S_{11}$ response of antenna is affected as the fracture is introduced into the limb phantom. There is a $3.5 \mathrm{~dB}$ rise at $3 \mathrm{GHz}$ between the steps where the bone is healed ( $0 \%$ damage) and where fracture exists, indicating that the introduction of a fracture consisting of higher permittivity and conductivity values to that of the bone near the monopole can affect its impedance. In order to further explore the changes in the response of the antennas, the propagation among the two monopoles is investigated (see Fig. 5).

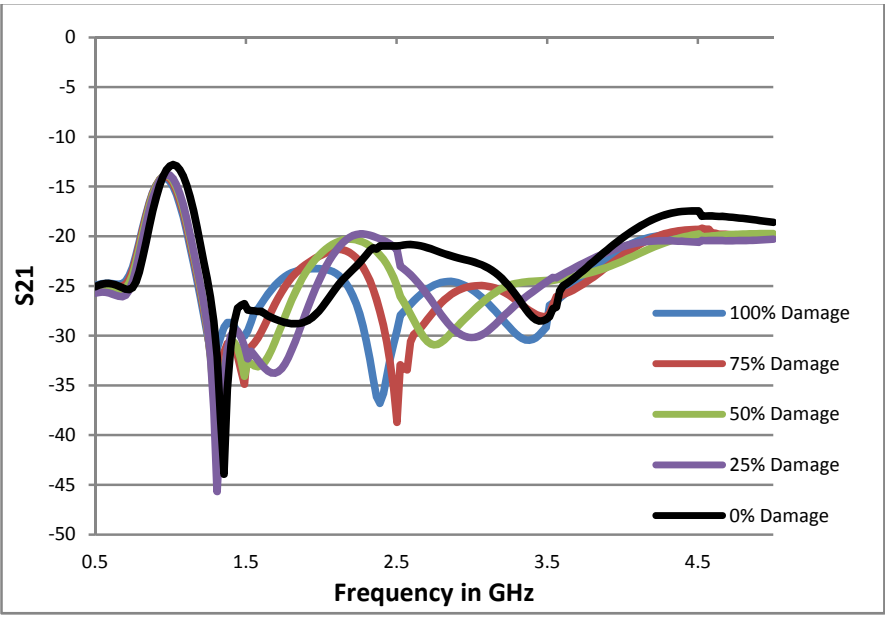

Figure 5: The $S_{21}$ response of the monopoles for the five steps of the bone fracture condition

According to the results shown in Figure 5, as the fracture changes from blood to bone, there is a shift in $S_{21}$ at $2.4 \mathrm{GHz}$ for $150 \mathrm{MHz}$ between $100 \%$ and $75 \%$ damage and a $250 \mathrm{MHz}$ shift between $75 \%$ to $50 \%$ and $50 \%$ to $25 \%$ damage. The shift between $25 \%$ and $0 \%$ damage were the fracture completely heals is at least at $450 \mathrm{MHz}$. These changes in the simulated system indicate that there is a possibility to monitor the condition of a fracture as it gradually heals by investigating the changes in $S_{11}$ and $S_{21}$.

\section{CONCLUSION}

An antenna system consisting of two implanted monopoles attached into two groundplanes outside the limb phantom has been proposed. The $S_{21}$ response of the system has been shown to shift to a higher frequency as the fracture between the monopoles healed by turning from blood to bone marrow and bone cortical. This occurs due to the change of the dielectric properties of the fracture, in between the monopoles, in terms of relative permittivity and conductivity. As the values of $\varepsilon_{r}$ and $\sigma$ transition from the high values of blood to the lower values of bone cortical, the propagation medium is affected. Future advances of the proposed system include different monopole designs such as in the form of needles that will make application into the muscle an easier task for the doctors and additional InVitro measurements using sophisticated multilayer phantoms and lamb joints.

\section{REFERENCES}

[1] J. Kim and Y. Rahmat-Samii, "Implanted antennas inside a human body: Simulations, designs, and characterizations," IEEE Trans. Microw. Theory Tech., vol. 52, no. 8, pp. 1934-1943, 2004.

[2] P. Soontornpipit, C. M. Furse, and Y. C. Chung, "Design of implantable microstrip antenna for communication with medical implants," IEEE Trans. Microw. Theory Tech., vol. 52, no. 8, pp. 1944-1951, 2004

[3] T. Karacolak, A. Z. Hood, and E. Topsakal, "Design of a dual-band implantable antenna and development of skin mimicking gels for continuous glucose monitoring," IEEE Trans. Microw. Theory Tech., vol. 56, no. 4, pp. 1001-1008, 2008.

W. Xia, K. Saito, M. Takahashi, and K. Ito, "Performances of an implanted cavity slot antenna embedded in the human arm," IEEE Trans. Antennas Propag., vol. 57, no. 4, pp. 894-899, 2009.

[5] R. Warty, M. R. Tofighi, U. Kawoos, and A. Rosen, "Characterization of implantable antennas for intracranial pressure monitoring: Reflection by and transmission through a scalp phantom," IEEE Trans. Microw. Theory Tech., vol. 56, no. 10, pp. 2366-2376, 2008.

[6] S. Soora, K. Gosalia, M. S. Humayun, and G. Lazzi, “A comparison of two and three dimensional dipole antennas for an implantable retinal prosthesis," IEEE Trans. Antennas Propag., vol. 56, no. 3, pp. 622-629, 2008.

[7] W. G. Whittow, R. M. Edwards, C. J. Panagamuwa, and J. C. Vardaxoglou, "Effect of tongue jewellery and orthodontist metallic braces on the SAR due to mobile phones in different anatomical human head models including children," 2008 Loughborough. Antennas Propag. Conf. LAPC, pp. 293-296, 2008.

C. J. Panagamuwa, W. G. Whittow, R. M. Edwards, and J. C. Vardaxoglou, "A Study of the Effects of Metallic Pins on SAR using a Specific Anthropomorphic Mannequin (SAM) Head Phantom," Antennas Propagation, 2007. EuCAP 2007. Second Eur. Conf., no. EuCAP, pp. 1-6, 2007.

[9] T. Karacolak, R. Cooper, and E. Topsakal, "Electrical properties of rat skin and design of implantable antennas for medical wireless telemetry," IEEE Trans. Antennas Propag., vol. 57, no. 9, pp. 28062812, 2009.

[10] J. Abadia, F. Merli, J. F. Zurcher, J. R. Mosig, and A. K. Skrivervik, "3D-Spiral small antenna design and realization for biomedical telemetry in the MICS band," Radioengineering, vol. 18, no. 4, pp. 359-367, 2009. 
[11] E. Y. Chow, C. L. Yang, A. Chlebowski, S. Moon, W. J. Chappell, and P. P. Irazoqui, "Implantable wireless telemetry boards for in Vivo transocular transmission," IEEE Trans. Microw. Theory Tech., vol. 56, no. 12, pp. 3200-3208, 2008.

[12] J. M. Felício, C. A. Fernandes, and R. Jorge, "Wideband Implantable Antenna for Body-Area High Data Rate Impulse Radio Communication," vol. 64, no. c, pp. 1932-1940, 2016.

[13] S. Bakogianni and S. Koulouridis, "Performance of a Novel Miniature Antenna Implanted into the Human Trunk for Medical Telemetry Applications," in 2015 9th European Conference on Antennas and Propagation (EuCAP), 2015, vol. 4, pp. $1-5$.

[14] Z. N. Chen, G. C. Liu, and T. S. P. See, "Transmission of RF signals between MICS loop antennas in free space and implanted in the human head," IEEE Trans. Antennas Propag., vol. 57, no. 6, pp. $1850-1854,2009$.

[15] K. Gosalia, M. S. Humayun, and G. Lazzi, "Impedance matching and implementation of planar space-filling dipoles as intraocular implanted antennas in a retinal prosthesis," IEEE Trans. Antennas Propag., vol. 53, no. 8, pp. 2365-2373, 2005.

[16] P. M. Izdebski, H. Rajagopalan, and Y. Rahmat-Samii, "Conformal ingestible capsule antenna: A novel chandelier meandered design," IEEE Trans. Antennas Propag., vol. 57, no. 4, pp. 900-909, 2009.

[17] M. Z. Azad and M. Ali, "A miniature implanted inverted-F antenna for GPS application," IEEE Trans. Antennas Propag., vol. 57, pp.
1854-1858, 2009.

[18] M. W. A. Khan, T. Bjorninen, L. Sydanheimo, and L. Ukkonen, "Characterization of Two-Turns External Loop Antenna With Magnetic Core for Efficient Wireless Powering of Cortical Implants," IEEE Antennas Wirel. Propag. Lett., vol. 15, pp. 1410$1413,2016$.

[19] K. D. Hankenson, G. Zimmerman, and R. Marcucio, "Biological perspectives of delayed fracture healing," Injury, vol. 45, pp. S8S15, 2014.

[20] S. Symeonidis, C. Torres-Sanchez, C. Panagamuwa, and W. G. Whittow, "An Implanted Antenna System for the Monitoring of Bioresorbability of a Biocompatible Scaffold Embedded into a Bone Fracture," Mobihealth, pp. 1-4, 2015.

[21] S. Symeonidis, W. G. Whittow, C. J. Panagamuwa, and M. Zecca, "An Implanted Antenna System for the Monitoring of the Healing of Bone Fractures," 2015 Loughborough. Antennas Propag. Conf., pp. 1-4, 2015.

[22] C. Gabriel, "Compilation of the Dielectric Properties of Body Tissues at RF and Microwave Frequencies.," Environ. Heal., vol. Report No., no. June, p. 21, 1996.

[23] S. Gabriel, R. W. Lau, and C. Gabriel, "The dielectric properties of biological tissues: II. Measurements in the frequency range $10 \mathrm{~Hz}$ to 20 GHz.," Phys. Med. Biol., vol. 41, no. 11, pp. 2251-2269, 1996. 